\title{
Strategizing Concept and a Changing Economy
}

\author{
Nikonova A.A. \\ Central Economics and Mathematics Institute of the Russian Academy of Sciences, \\ Moscow, Russia, \\ prettyal@cemi.rssi.ru
}

\begin{abstract}
Fundamental changes in the concept of strategy creation are discussed in the context of changes that highlight the essence of modern economics. The results refer to threats, divided into five pillars: (1) inadequate methodology and techniques create misconceptions about economic units within the socio-economic system; (2) invalid imputed data; (3) the human factor, the interests of different actors; (4) unstable internal and external environment; (5) the problem of the correspondence of public institutions and state institutions to the changing economy. It is considered that most of the threats are caused by the unsatisfactory quality of strategic planning in Russia. The novelty of the approach lies in the fact that the proposed method of developing a strategy is much better adapted to all the noted challenges and new opportunities than the methods applied in practice, since it is based on systemic economic theory, which is more applicable than all known theories and concepts for describing the problems of diversity of the new economy and represents the systemic integrity of the economy and society more realistically. The proposed concept of strategic development is designed to implement system thinking within the framework of systems analysis and synthesis of the new economy and the alignment of local interests with the goals of the economy as a whole.
\end{abstract}

Keywords-new economy, strategy, threats, actors, system approach, strategizing

\section{INTRODUCTION}

The study examines the methodological and practical issues of creating strategies in the context of significant changes in the economy and society. Today's economy is rapidly changing both in innovation trends and in technological complexity, communication methods, and the increasing influence of the human factor.

The main characteristics of the new economy can be formulated in the form of four pillars of characteristics: (1) fundamentally new technologies, including technologies of Industry 4.0; (2) new relationships between economic agents, new ways of doing business, including virtual ones; (3) open innovation as a global scientific and technological trend; (4) high importance of human potential - motivation, interests of individuals and social groups; as well as cognitive factors, human abilities, talents. On the one hand, these changes create opportunities and stimulate technological development. On the other hand, they encourage multiple phenomena of uncertainty in economy.
Thus, the main obstacle for the management of the mesoand macroeconomics, as well as for the management of the enterprise, is to take into account most of all changes to make acceptable decisions. Otherwise, they can significantly complicate further competitive sustainable development of the economy and its divisions.Unresolved internal problems of the Russian economy, combined with cardinal global structural and technological shifts, exacerbate such threats. In this regard, both the adjustment of the existing concept of strategic planning of changes and the improvement of models for making strategic decisions are required. Fundamental changes, increasing complexity and diversity of internal and external factors can increase the threat of inconsistency between the management system and the economy in accordance with the principle of required diversity [1]. Thus, we can conclude that the risks are largely associated with inadequate quality of planning and management.

The analysis is focused on the scientific and technological strategy, since it is most affected by the current trends in a new economy. The first part of the article discusses substantial problems in the development and implementation of technology strategies in Russia. An unsystematic approach to strategic decision-making neither focuses enough of the country's opportunities and advantages in the development of new industries, nor takes into account core system contradictions in economic and society. The most important complementary parts in strategy creation process are ignored.

The article discusses some of the immense threats; they are divided into five pillars. They increase the uncertainty of both the environment for the functioning of economic entities and the situation in which decisions are made. This is primarily due to the insufficient preparation of the concept of strategic planning and management aimed at technological modernization in Russia. The second part of the article proposes a method for developing a strategy for changes in the new economy, which helps to satisfactorily respond to the challenges of the new economy and obtain strategic decisions agreed with all stakeholders, involving them in setting goals and choosing directions for further economic development. The proposed approach focuses both on the key issues of the new economy and on competitive opportunities. The application of these systemic frameworks to the mechanisms for building a strategy allows them to be brought in line with modern trends, taking into account the opportunities, threats and ways of 
developing the national socio-economic system (SES).

\section{RESULTS}

\section{A. Threats in strategy formation}

Key threats relate to strategic planning methodologies and techniques, as well as issues of improving the environment conducive to innovation. According to G. Mintzberg, a strategy should be considered as "five Ps": perspective, plan, ploy, pattern, position [2].

We divided fields of challenges and threats in the strategic planning process into five pillars in a similar way, depending on the role of the threat factors in strategic formation (Fig. 1).

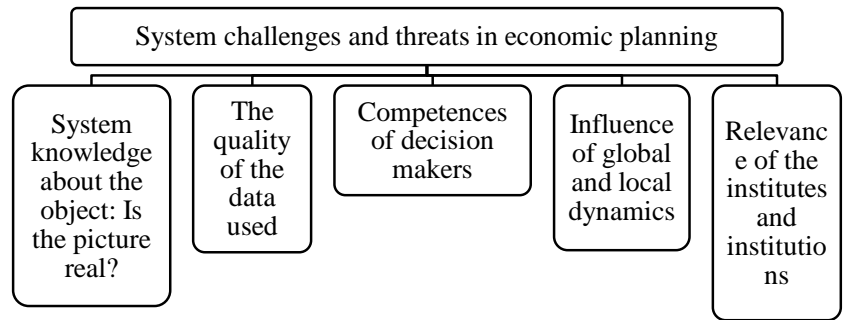

Fig 1. Major challenges and threats in strategic planning of the new economy

The first pillar is mainly related to inconsistencies in methodology and planning methods [3]:

- Degree of reliability of identification of the real image of the economy, as well as cause-and-effect relationships as a result of system analysis and synthesis of the changing economic system.

- Defining the boundaries of the system as a planning object.

- Reflection of the system complexity and nonstationarity of the economy when building a strategy.

- Representation of the completeness of interests of stakeholders and agreement of the parties.

The second pillar of threats applies to the issues of data quality in the assessing the situation and capabilities:

- Degree of consistency, reliability of data on economic system and the environment.

- Sufficiency and completeness of information base.

- Data availability at different stages of decision making.

The third pillar focuses on the possibilities and capabilities of both the planning entities and decision makers at all the economic levels to assess correctly the situation and to make decisions adequate to the priorities of the socio-economic system and also to the subsystems' goals with the purpose to maintain system integrity and sustain technological development:

The study is supported by the Russian Foundation for Basic Research, No 18-010-01028a, "Methodology and Tools for Strategizing Technological Developments in Economic Systems at the Different Hierarchy Levels,

Taking into Account the Requirements of Industry 4.0 for Nonstationary Russian Economy"
- Knowledge and decision makers' skills to implement suitable methods in planning and governance.

- The desire and motivation to make adequate decisions in the interests of both the country and business.

- Human values, aspirations, urges that influence the choice of strategic decisions.

The fourth pillar is related to the possibilities to adapt SES to the realities of the surrounded world while the SES is exposed to the challenges rapid changes and dynamic innovation trends:

- Poor forecasting of influence of uncertainty of the internal situation and the external environment.

- Problematic assessment of the relative significance of the influence of external factors in comparison with internal unsolved problems.

- Not always sufficient focus on intellectual factors in terms of supporting science and education as the leading drivers of sustainable development of the socioeconomic system.

- Poorly predictable, but quite noticeable influence of political factors on economic decision making.

The fifth pillar of threats is caused by the challenges of compliance of society institutions and state institutes with the requirements of the new economy, including the quality of the regulatory environment:

- Quality of the legislative base to develop innovation in harmony of all sectors of socio-economic system.

- Distribution of powers and responsibilities of officials.

- Problematic degree of both centralization and coordination in making decisions.

One can see some typical threats in the Russian practice of technological strategy constructing on the following examples. In the latest report of the FAS, the Central Bank of the Russian Federation was named as the greatest risk factor for the Russian economy due to its inadequate decisions.

The difference in the goals between influential elites and society, as well as apriority in priority setting methods (including volitional approach) lead to the selection of such priorities and instruments of governmental policies that they do not correspond neither to the country's current tasks, nor the system ability to achieve goals in the accepted technological strategy of RF to 2035 [4].

The only indicator of the "Innovation Russia-2020" Strategy has been achieved - it is the number of publications, but this had no effect on reducing the technological gap between the Russian Federation and the leading countries.

Enterprises engaged in technological innovation as percentage of all enterprises had been planned to be increased to $40 \%$ by 2020 , but it remained almost unchanged at $7.5 \%$ yet ${ }^{1}$. In the "Strategy of the Scientific and Technological Development of the Russian Federation", ones wanted this indicator to be increased somehow to $50 \%$ by 2024 . It is not 
clear how this can be done, since the goals have been chosen out of account of the capabilities or obstacles in the side of socio-economic system sectors. Major internal and external trends and factors have not been taken into account [4]. All these threats lead to risks to be increased greatly.

These and some other threats impede Russia's transition to a new technological order in all its manifestations: innovative enterprises, advanced technologies, industrial modernization, new industries, modern activities, close interaction between actors, intellectual drivers of economic growth.

\section{B. Trends and drivers of innovation activity: the experience of Russian Federation}

Successful creation, diffusion, transfer innovations require the ideal combination of four components in the form of their harmonious synthesis in the national economy: 1) an appropriate technics and technological level of industrial development ; 2) science, education, human development and innovation readiness, including the readiness of society; 3 ) adequate financial support; 4) favorable institutions for innovation. There are some metrics below that demonstrate the most destructive forces which characterize the threats to the Russian Federation innovation strategy from the side of the main global drivers of innovation.

1. Technological basis. Renovation rates of fixed assets in manufacturing sector declined from 6.8 to 5.7 (2008-2019) ${ }^{2}$. Fixed assets depreciation rate increased from $46.8 \%$ in industry in a whole to $50.6 \%$ in manufacturing, 55.6 in mining and quarrying (2000-2019), Share of fully depreciated machines and equipment of commercial organizations in manufacturing increased from $17.8 \%$ to $25.7 \%(2008-2019)^{3}$.

2. Human capability, Science and Education. Patent applications filed in Russia by residents to GDP at PPP fell in 4.3 times (2000-2018); researchers per population declined 3 times (1991-2018) ${ }^{4}$. Just a few (12\%) people aged 25-64 years participate in continuing formal or non-formal education that is 2-5 times less than in European countries ${ }^{5}$. Only $1 / 3$ of respondents consider profession of a scientist to be prestigious ${ }^{6}$. Gross domestic expenditure on R\&D of GDP accounts for $1.0 \%$; expenditure on education $-3.7 \%$ of GDP; that are lower in percentage terms than in many developing countries. RF ranks 113 th in the ranking of social capacity ${ }^{7}$.

3. Funding. BERD account for only $17.3 \%$ of the GERD; GERD financed by abroad $-0.02 \%{ }^{8}$. Russia ranks 94rd in the world ranking of venture capital availability ${ }^{9}$

4. Institution environment. Russia ranks 96th in Regulatory quality index; 110th - in Rule of law index; 87th - in terms of
Government effectiveness ${ }^{10}$.

\section{DISCUSSION}

\section{A. System analysis in strategic planning}

System analysis is considered as a process aimed to obtain the most realistic picture of capabilities of the SES in changing world. It isn't limited by the framework of SWOT-model. From the view of Systems thinking it supposes to exam diverse fields and influences of human life and economic activities [5]. One of the questions is whether a system analysis both of the threats and opportunities had been executed before strategic decisions have been made in the Russian technological strategies as till 2020 and till 2030. The results of our investigation reveal some weaknesses of the Russian economy capacity for innovation [4]. For example, global innovation trends are focused on such drivers of knowledge creation and absorption of new technologies as cognitive factors, talents and especial abilities of individuals. Therefore they should be supported by the strategic priorities. However, this is not given the desired attention in the Russian strategies.

The system analysis reveals significant gaps in almost every pool of innovation opportunities. On the contrary the weighty advantages that lie in national resources, vast territorial advantages and the intellectual potential of Russians have not actually been embodied in the practice of transition to a technological model of economic growth. The reason is that they are not sufficiently supported by appropriate strategies, priorities and support measures that would be of interest to all economic agents. In addition, an extremely low level of trust in society prevents the development of new types of relations and communications while they are inherent in the new economy.

Systematic assessments of innovation capacity indicate areas of threats to the strategy of a new economic development. Such threats should be properly overthink from the view of the systemic economic paradigm $[6 ; 7]$ in terms of adequate planning and governance, taking into account all the opportunities in the strategy building process, in order to outline ways to improve all components of the new economy's capabilities. They relate to the technical basis of industrial enterprises, production facilities, and suitable regulatory framework for innovation. First of all, the creating of a favorable intellectual environment, including continuous learning processes, $\mathrm{R} \& \mathrm{D}$, development of talents, as cognitive opportunities are decisive factors in the growth of the new economy.
${ }^{2}$ Rosstat: Official stat:: Technological development of economic sectors. URL: https://rosstat.gov.ru/folder/11189.

${ }^{3}$ Russia in Figures. 2003: Stat. Handbook. Moscow: Goskomstat of Russia, 2003.

Russia in Figures. 2020: Stat. Handbook. Moscow: Rosstat, 2020;

Russian Statistical Yearbook 2019: Stat. book. Moscow: Rosstat, 2019;

Rosstat: Official stat.: Entrepreneurship: Fixed Assets. URL:

https://rosstat.gov.ru/free_doc/new_site/business/osnfond/DPI_of.htm.

${ }^{4}$ Russia in Figures. 2003; Russia in Figures. 2020.

${ }^{5}$ Indicators of Education in the Russian Federation: 2020 : Data Book. / N. Bondarenko, D. Borodina, L. Gokhberg, et al. Moscow : HSE, 2020, p. 79. URL: https://issek.hse.ru/mirror/pubs/share/352549981.pdf.

${ }^{6}$ Science and Technology Indicators: 2018 : Data Book / N. Gorodnikova, L. Gokhberg, K. Ditkovskiy et al. Moscow: HSE, 2018. URL:
https://www.hse.ru/data/2018/02/12/1162058327/Science_and_Technology_I ndicators_2018.pdf.

${ }^{7}$ The Global Competitiveness Report 2019. Geneva, Switzerland: WEF, 2019, p. 483. URL:

http://www3.weforum.org/docs/WEF_TheGlobalCompetitivenessReport2019. pdf;

The Global Innovation Index 2020. Who Will Finance Innovation? Ithaca, Fontainebleau, and Geneva: Cornell University, INSEAD, and WIPO, 2020, p. 315. URL:

https://www.wipo.int/edocs/pubdocs/en/wipo_pub_gii_2020.pdf.

${ }^{8}$ Russia in figures 2020 .

${ }^{9}$ The Global Innovation Index, 2020, p. 315.

${ }^{10} \mathrm{Ibid}$. 


\section{B. Strategizing: Systemic concept for strategic planning}

This part of the study is aimed at developing the conceptual foundations of strategic planning for a new economy in an environment of increased uncertainty associated with modern shifts in technology, in the structure of factors, in the relationship of economic agents, in the ways of organizing of economic activity and innovation. New technologies and production methods, including virtual networks, are changing the relationship between key actors. On the one hand, such changes make it possible for all players to work together at different stages of creating a strategy or new technologies based on an open system model. On the other hand, they require special methods and tools for setting goals and predicting the modes of promising activities in an uncertain situation. The demands of the changing SES can be satisfied using a systemic methodology to develop of the appropriate model of a new economy strategy.

The emergence of the term "strategizing" in relation to economics is associated with the work of O. Williamson [8]. Strategizing is assumed as a set of processes of forecasting, planning, managing and shaping the future, relying on a multifaceted description of the reality, knowledge about the rules of change and on the ability to respond to changing reality. However, the term and the corresponding understanding of planning haven't been actualized within the framework of systemic economic theory, especially since they haven't been institutionalized in the Russian practice of strategic planning and governance in response to the challenges and threats which arose as the result of mismatching of interests of actors and sectors in the economy. In addition, methodological procedures have not been developed for strategizing the economy at different levels of its hierarchy. Whereas it is precisely strategizing that contributes to the coordination of the SES sectors and to the harmonization of various actors' preferences and goals. Strategizing is a process of team-based strategy formation [9] in changing economy. It is aimed to respond to many challenges of the new economy taking into account the growing diversity of internal factors and the external environment in its rapid dynamics.

Strategizing is a process system. It includes the special procedures for preparing, making and coordinating long-term decisions. Strategizing is aimed to maintaining the integrity of the SES, promoting sustainable economic growth and harmonious development of all sectors. By strategizing, we mean the process of strategy formation in a wide context of related actions that are absent in traditional practice, including (1) formulating hypotheses, (2) preparation of information, (3) system analysis, (4) development of the desired image of SES, (5) setting goals as an iterative process based on taking into account the preferences of key economic agents, (6) a conclusion about the possibility of achieving goals, (7) an analytical assessment of the results, (8) clarification of developing activities and possible governance impacts.

The concept is based on the system economic theory [10, $11]$ and on the systemic economic paradigm [6, 7, 12]. The novelty of the approach is that it is devoid of the flaws which can be observed in existing planning model, since the proposed strategizing model as a process includes the quite important complementary procedures of strategy building, which are absent in the now days practice. They are comprehensive system social-economic analysis, iterative goal setting, designing of prospect image of the system, reflexive analysis of the results, and some other steps within system thinking procedures. Ignoring these steps leads to the threat of making the wrong decisions, as discussed above.

\section{Strategizing model}

Strategizing model is quite different from building a strategy in practice; this can be verified by comparing two block models (Fig. 2, 3). Unlike the traditional approach, the strategizing model includes such interactive procedures that help improve the quality of the strategy, bring it in line with global trends, national goals and local interests of business entities.

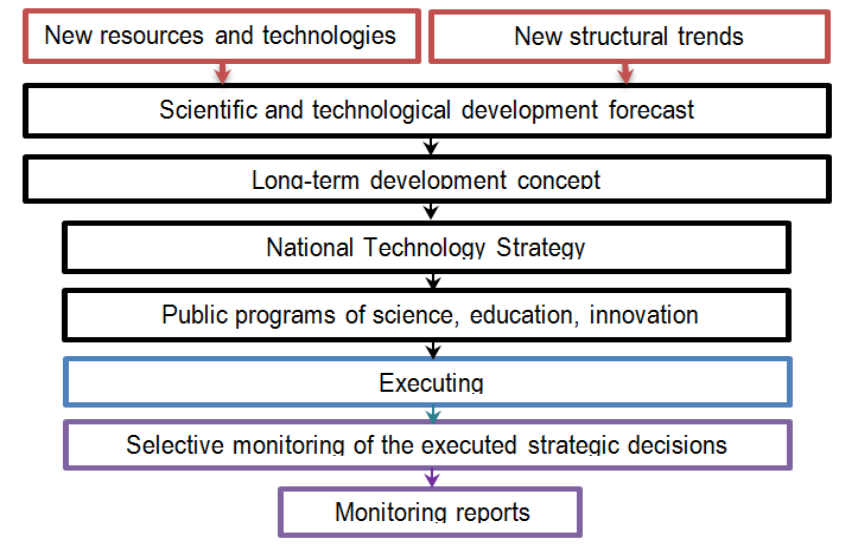

Fig 2. Strategic planning scheme in current practice in the Russian Federation

The strategizing model introduces additional steps and procedures into existing strategy building practices. The most significant differences are listed below, they represent such advantages of proposed model that meet the requirements of the new economy and facilitate coordination in the development of all sectors of the SES.

(1) System analysis of an economic object and environment, as well as all procedures for preparing information those precede it. The task is a systematic assessment of the potential of the system development under the influence of a complex of factor influences and multidirectional trends in the environment. Some of them cannot be described quantitatively (such as talents, creativity, cognitive factors); for this, heuristic procedures and expert methods can be used. System assessments provide a realistic description of the economic system and its environment, firstly, in dynamics; secondly, in different aspects, depending on the subject of strategizing.

(2) Generation of strategy scenarios [13] should be implemented in interactive mode with on-line technology that facilitates virtual stakeholder communication and allows executing of multiple iterations of scenarios calculation.

(3) Designing the image of the future economy as a holistic and balanced system allows all players to get intelligible answer to the key question: where are we going.

(4) Goal-setting is a process; it includes several iterations, in which the imperatives of economic development would be compared with the opportunities and development capacity of the system. In addition, it is assumed that all parties are involved in order to coordinate the interests of economic 
entities, both among themselves and with the development guidelines of economic sectors. (Such a strategic planning procedure is extremely needed, but it is quite multifaceted in its organizational way in the form of a multi-stage process. It is absent in the existing planning practice in the Russian Federation.)

(5) Feedbacks in the strategizing model help to adjust the planning and governance system to the object (economy), which changes as a result of the implementation of the strategic decisions.

(6) Reflexing is a special stage of critical analysis of the information on the obtained positive and negative effects. Reflexing contributes to clarification and expanding knowledge about the system, environment, and cause-and-effect relationships. It helps to appreciate and recognize the mistakes that led to failures. Reflexing helps to verify the decisions that have been made as well as to comprehend the prospects for further development.

(7) Tricky issues such as the need for and the possibility of adjusting the strategy and methods of supporting strategic decisions are assessed in each particular case with the involvement of stakeholders and using the data obtained along the negative feedbacks.

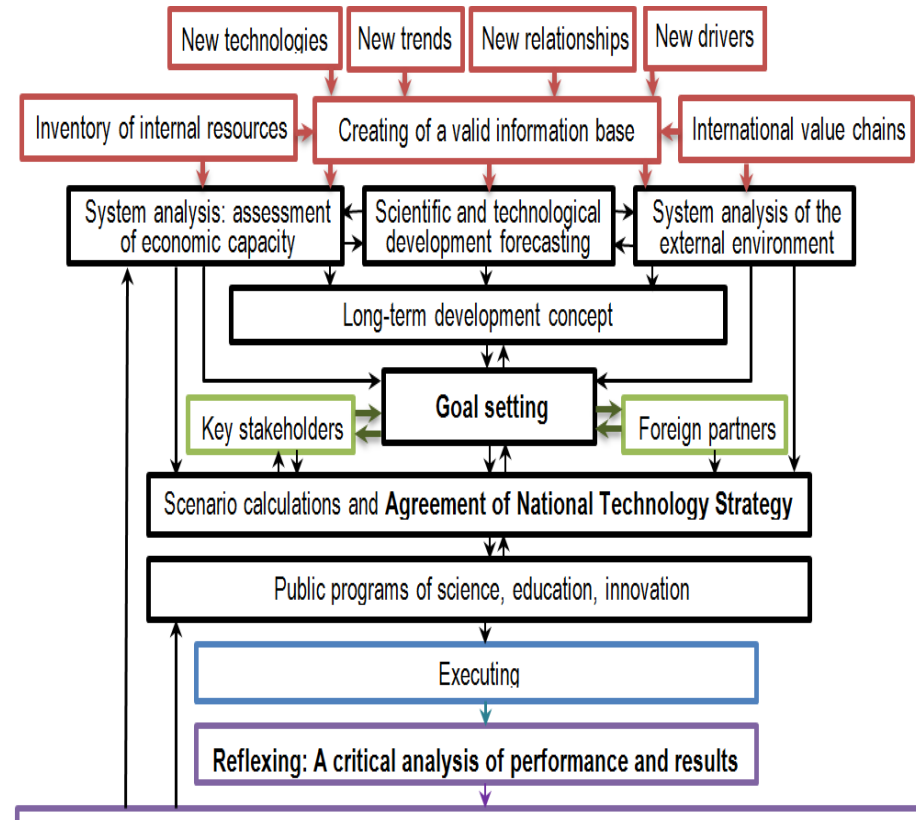

Refining of knowledge about the s/stem, rethinking the concept of development and governance methods

Fig. 3. The strategizing model as a multi-stage iterative process

The absence of such stages in the practice of strategy formation causes threats associated with the inadequacy of decisions, as this is discussed above. On the contrary, strategizing is not limited to the framework of the formulation of strategic documents, but extends strategizing actions up to the execution of the decisions, a reflexive analysis of changes in the socio-economic system, revision of ideas about the future image of planning objects, a rethinking of the image of the future system, perhaps with a possible correction of some goals and methods of support.

Thus, the system approach embodied in the strategizing model helps to eliminate the above threats that arise at different stages of building a strategy for a changing economy.

\section{THE FINDINGS AND CONCLUSIONS OF THE PAPER}

Dynamic character of a new economy causes the threats in growing economic uncertainty but at the same time gives immense opportunities to technological upgrading if the new challenges would be carefully interpreted and accepted in the process of strategies building. For this it needs to improve methodology and instruments to make decisions.

The methodological dysfunction of the strategic planning concept as well as practiced one creates the threats in the technological development.

The improvement of the concept of creating a strategy refers to the methodology and planning models, based on the system economic theory taking into accounts the imperatives and characteristics of the new economy: technological capabilities, cognitive drivers of innovation, new ways of connecting players, and expanded network structures. The proposed strategizing model includes several iterative procedures that make decisions that should be consistent with internal capabilities and external challenges. System thinking of the nature of changes in assessing the new economy (including the interactions of actors) and the impact of such changes on economic sectors helps to align interests and better justify decisions.

A serious problem in the implementation of the strategizing concept is the instrumental support of poorly formalized procedures, including methods of coordinating the preferences of players with opposite interests and views on the principal points of further development of the national economy.

We intend to improve the concept of strategizing scientific and technological developments of the new economy as a tool for transforming SES on the platform of creating innovation ecosystems.

\section{References}

[1] W.R. Ashby, An Introduction to Cybernetics. London: Chapman and Hall, 1956. DOI: https://doi.org/10.5962/bhl.title.5851

[2] H. Mintzberg, B. Ahlstrand, and J. Lampel, Strategy safari: a guided tour through the wilds of strategic management, NY: THE FREE PRES, 1998

[3] A. Varshavskiy, "On the strategy of scientific and technological development of the Russian economy", Society and economy, 2017, vol. 6, pp. 5-27.

[4] A.A. Nikonova, "Sistemic requirements and their implementation in the science and technological strategy in Russia", Economic science in contemporary Russia, 2019, vol. 1(84), pp. 117-134. (In Russ.). DOI 10.33293/1609-1442-2019-1(84)-117-134

[5] F. Capra, and P. Luisi, The Systems View of Life: A Unifying Vision, Chapter in the book: The rise of systems thinking, Cambridge: Cambridge University Press, 2014. DOI: https://doi.org/10.1017/CBO9780511895555

[6] Y.A. Kornai, "System paradigm”, Economics Issues, 2002, vol. 4, pp. 1012.

[7] G.B. Kleiner, "System paradigm and enterprise theory", Economics Issues, 2002, vol. 10, pp. 47-69.

[8] O.E. Williamson, "Strategizing, Economizing, and Economic Organization", Strategic Management Journal: Special Issue, 1991, vol. 12, pp. 75-94

[9] A. Calabrese, and R. Costa, "Strategic thinking and business innovation: abduction as cognitive element of leaders' strategizing", Journal of 
Engineering and Technology. Management, 2015, vol. 38, pp. 24-36. DOI: https://doi.org/10.1016/j.jengtecman.2015.06.001

[10] G.M. Hodgson, "Economics and Systems Theory", Journal of Economic Studies, 1987, vol. 14(4), pp. 65-86. DOI https://doi.org/10.1108/eb002655

[11] G.B. Kleiner, "New theory of Economic Systems and Its Application", RAS Bulletin, 2011, vol. 81(9), pp. 794-811.

[12] G. Kleiner, "System Economics as a Platform for development of modern
Economic Theory", Economics Issues, 2013, vol. 6, pp. 4-28. DOI: https://doi.org/10.32609/0042-8736-2013-6-4-28

[13] T. Lehr, U. Lorenz, M. Willert, and R. Rohrbeck, "Scenario-based strategizing: Advancing the applicability in strategists' teams", Technological Forecasting and Social Change, 2017, vol. 124, pp. 214224. DOI: https://doi.org/10.1016/j.techfore.2017.06.026 